\title{
Análise do empoderamento tecnológico pelo PIBID
}

\author{
Analysis of technological empowerment by the PIBID
}

\author{
Douglas Silva Fonseca ${ }^{1}$ \\ Éliton Meireles de Moura ${ }^{2}$
}

\begin{abstract}
Resumo. Nesse artigo buscamos compreender como o Programa Institucional de Bolsas de Iniciação à Docência (PIBID) se tornou importante como ferramenta para empoderar tecnologicamente a formação de futuros professores. Apresentamos inicialmente algumas políticas públicas, dentre elas o PIBID que veio diminuir a distância entre o Ensino Superior praticado nas Universidades e Institutos com a Educação Básica de nossas escolas públicas brasileiras, e logo depois mostramos números sobre a expansão deste programa. O uso de ferramentas tecnológicas dentro das salas de aula se torna mais frequente com o desenvolvimento da própria tecnologia. Acreditamos que essa inserção no contexto escolar além de inevitável é também necessária. O fato é que os problemas estruturais e de caráter formativo são evidentes em escolas e universidades. O restante do artigo se baseia em um estudo de doutorado e outro de mestrado que trataram sobre o cenário macro e micro do PIBID para o trabalho com uso das tecnologias digitais de informação e comunicação, em subprojetos de matemática, por todo o território brasileiro no decorrer destes quase 10 anos de atuação do programa demonstrando que houve um amadurecimento devido à compreensão do Cotidiano Escolar, principalmente pela importância dada ao trabalho coletivo e diálogo com pensamentos diferentes, resultando reflexão sistemática sobre as práticas pedagógicas.
\end{abstract}

Palavras-chave. Formação de professores, Pibid, políticas públicas para educação.

Abstract. In this paper, we seek to understand how the Institutional Teaching Initiation Scholarship Program (PIBID) has become an important tool to technologically empower the training of future teachers. Initially, we present some public policies, among them the

\footnotetext{
${ }^{1}$ Universidade Federal do Tocantins, Campus de Araguaína, douglasfonseca@mail.uft.edu.br

${ }^{2}$ Universidade de São Paulo (FEUSP), elitonmoura@usp.br
} 
PIBID, that reduced the distance between what we teach in Higher Education at the Universities and Institutes, with what we found in the Basic Education of our Brazilian public schools, and, soon after, we show numbers about the expansion of this specific program. The use of technological tools within the classroom becomes more frequent with the development of the technology itself. We believe that this insertion in the school context is not only inevitable but also necessary. The fact is that structural and formative problems are evident in schools and universities. Given that there are numerous structural and formative problems in schools and universities, this paper is based on a doctoral and master's degree study that dealt with PIBID's macro and micro scenario for working with the use of digital information and communication technologies in mathematical sub projects throughout Brazil. We could verify that, in almost 10 years of the program's performance, there was a growing maturity in the comprehension of the school's daily life, mainly due to the importance attributed to the collective work and the dialogue with different thoughts, resulting in a systematic reflection on the pedagogical practices.

Keywords. Teacher training, PIBID, public policy for education.

\title{
1 A constituição de um cenário em números
}

\begin{abstract}
Ninguém poderá ser um bom professor sem dedicação, preocupação com o próximo, sem amor num sentido amplo. O professor passa ao próximo aquilo que ninguém pode tirar de alguém, que é conhecimento. Conhecimento só pode ser passado adiante por meio de uma doação. $\mathrm{O}$ verdadeiro professor passa o que sabe não em troca de um salário (pois se assim fosse melhor seria ficar calado 49 minutos!), mas somente porque quer ensinar, quer mostrar os truques e os macetes que conhece (D'AMBRÓSIO, 1996, p. 84).
\end{abstract}

Nos últimos anos do século passado, o país vivia momentos difíceis com grande ameaça da volta da inflação e elevadas taxas de desemprego, sem falar nas obrigatoriedades impostas pelo Fundo Monetário Internacional (FMI). Pouco era feito para mudar as desigualdades sociais no país, até que com a troca de presidência em 2003 um novo cenário foi criado. Baldijão e Zuleide $(2011$, p. 6) retrata a mudança deste cenário quando nos diz que:

Os dois governos liderados pelo presidente Lula e pelo Partido dos Trabalhadores (PT) mudaram esse quadro, transformando o Brasil em um dos principais países no cenário internacional, com uma política externa que prioriza os interesses nacionais e regionais, além de buscar mudar a histórica desigualdade nas relações Norte-Sul. O governo Lula chegou ao último ano de seu segundo 
mandato com um índice de aprovação acima dos 80 num evidente apoio às mudanças sentidas pela população (BALDIJÃO e ZULEIDE, 2011, p. 6).

Na área da Educação, alguns cenários foram fundamentais para o avanço do país. Tivemos fundadas 18 universidades federais espalhadas em várias regiões do território nacional, e também 282 escolas técnicas federais de ensino, que antes de 2002 eram 140. Foram ainda criados o Programa de Reestruturação e Expansão das Universidades Federais (REUNI), que estabelece aumento de recursos de custeio e de pessoal para as Universidades federais brasileiras; no Ensino Superior privado, o Programa Universidade para Todos (Prouni) que consistiu em concessões de bolsas de estudos integrais e parciais para estudantes com renda per capita de até três salários mínimos. Este último, que em 2005 tinha cerca de 95 mil bolsistas, terminou o ano de 2010 atingindo mais de 740 mil bolsistas, segundo dados da Secretaria de Educação Superior do Ministério da Educação (Sesu/MEC).

Tivemos ainda políticas públicas de educação incentivando cursos de licenciatura no país, com a possibilidade de trabalho com Escolas Públicas de Educação Básica antecipando aos licenciandos uma troca de saberes e práticas na parceria universidade-escola básica, a fim de que este futuro professor pudesse, antes mesmo de seu Estágio Supervisionado que é obrigatório para sua formação, previr sua prática de atuação nas escolas. Diversos programas e projetos foram lançados nesse sentido, entre eles, o Programa de Consolidação das Licenciaturas (PRODOCÊNCIA); o Programa Observatório da Educação (OBEDUC); o Plano Nacional de Formação de Professores para Educação Básica (PARFOR); o Programa Novos Talentos; dentre outros.

Financiado pela Coordenação de Aperfeiçoamento de Pessoal de Nível Superior (CAPES) e pelo Fundo Nacional de Desenvolvimento da Educação (FNDE), com o apoio da Secretaria de Educação Superior (SESu) e do Ministério da Educação (MEC), o PIBID, apesar de ser lançado em 2007, iniciou os trabalhos a partir de 2009 demandando recursos de quase um bilhão e meio.

A partir daí, é possível perceber que o PIBID recebeu maior investimento comparado aos demais, e talvez isso evidencie uma grande aposta governamental para promover as licenciaturas. Lançado, inicialmente, para atuação nas disciplinas de Química, Física, Biologia e Matemática, devido à carência de profissionais nestas áreas, esperava-se que o PIBID se tornasse uma ferramenta de manutenção de licenciandos nas universidades bem como atração para outros ainda não ingressados nas universidades a se tornarem professores.

Nesse sentido, citamos as considerações de DANTAS (2013, p. 10) em sua dissertação de mestrado:

No atual contexto educacional e dos desafios acentuados diante de uma profis- 
FONSECA, D. S.; de MOURA, E. M.

\begin{tabular}{|c|c|c|c|c|c|c|}
\hline \multicolumn{7}{|c|}{ Recursos investidos da DEB (em Reais - R\$) } \\
\hline DEB $*$ & 2009 & 2010 & 2011 & 2012 & 2013 & TOTAL \\
\hline Parfor & $12.394 .341,09$ & $70.914 .408,33$ & $110.987,220,82$ & $162.895 .436,02$ & $171.919 .765,09$ & $529.111 .171,35$ \\
\hline Pibid & $20,041: 950,00$ & $80,398.941,22$ & $138.597 .928,92$ & $219.084 .614,74$ & $287.900 .596,63$ & $746.024 .031,51$ \\
\hline Obeduc & $8.195,310,63$ & $5.851 .075,25$ & $18.863 .568,37$ & $16.676 .004,54$ & $22,687.483,34$ & $72,273.442,13$ \\
\hline Prodocência & $4.180 .203,63$ & $6.729 .426,08$ & $2.431 .199,85$ & $2.470 .474,44$ & $36.200,00$ & $15.847,504,04$ \\
\hline Novos Talentos & - & $7.788 .894,45$ & $2.798 .072,00$ & $4.330 .579,63$ & $3.265 .992,04$ & $18.183 .538,12$ \\
\hline $\begin{array}{l}\text { Projetos } \\
\text { Especiais }\end{array}$ & $=$ & $6.329 .639,03$ & $9.512 .193,94$ & $15.664 .809,77$ & $14.133 .778,29$ & $45.640 .421,03$ \\
\hline Life & $=$ & $=$ & - & $14.314 .025,20$ & 0,00 & $14.314 .025,20$ \\
\hline $\begin{array}{l}\text { Outras despesas } \\
\text { (diarias, } \\
\text { passagens, etc) }\end{array}$ & - & $955.510,93$ & - & $4.371 .217,76$ & $854.949,53$ & $6.181 .678,22$ \\
\hline TOTAL & $44.811 .805,39$ & $178.967 .895,29$ & $283,190.183,90$ & 439.807 .162 .10 & $500.798 .764,92$ & $1.447 .575 .811,6$ \\
\hline
\end{tabular}

Figura 1: Recursos investidos Diretoria de Formação de Professores da Educação Básica (DEB). Os totais não incluem valores inscritos em restos a pagar não processados. Fonte: Relatório de Gestão da CAPES

são com pouco reconhecimento social e, consequentemente, com baixa atratividade aos jovens ingressantes nas universidades, a formação de professores tem se tornado no transcurso das últimas décadas um tema de relevância social. Diante deste cenário o PIBID vem tornando-se uma política pública muito importante de valorização do magistério, possibilitando aos licenciandos atuação no seu campo de trabalho, desde o início de sua formação, por meio de atividades que possibilitam a interação com professores e estudantes da educação básica e a articulação entre a universidade e as escolas (DANTAS, 2013, p. 10).

Pensando nisso, o programa foi alterado para atender todas as Licenciaturas responsáveis pela Educação Básica. O Decreto Federal n 7.219 de junho de 2010, que regulamentou o programa, determinava que:

O Programa Institucional de Bolsa de Iniciação à Docência - PIBID, executado no âmbito da Coordenação de Aperfeiçoamento de Pessoal de Nível Superior - CAPES, tem por finalidade fomentar a iniciação à docência, contribuindo para o aperfeiçoamento da formação de docentes em nível superior e para a melhoria de qualidade da educação básica pública brasileira (BRASIL, 2010).

Deste objetivo geral do PIBID, discorrem outros objetivos, específicos, assim estabelecidos pelo Decreto Federal, Educação Superior (2010, p. 26), dentre os quais destacamos:

I) incentivar a formação de professores para a educação básica, apoiando os estudantes que optam pela carreira docente; valorizar o magistério, contribuindo para a elevação da qualidade da escola pública;

II) inserir os licenciandos no cotidiano de escolas da rede pública de educação, promovendo a integração entre educação superior e educação básica; 


\begin{abstract}
III) proporcionar aos futuros professores participação em experiências metodológicas, tecnológicas e práticas docentes de caráter inovador e interdisciplinar e que busquem a superação de problemas identificados no processo de ensino-aprendizagem, levando em consideração o desempenho da escola em avaliações nacionais, como Provinha Brasil, Prova Brasil, SAEB, ENEM, entre outras;

O PIBID lançou oito (8) editais entre 2007 e 2013, destinado ao processo de implantação e expansão do programa no decorrer deste período. Uma das avaliações sobre o PIBID está descrita abaixo, quando GATTI e ANDRÉ (2013, p. 8) apud DEB, nos dizem no relatório 2009-2013 que:
\end{abstract}

Constata-se que o PIBID vem possibilitando, na visão de todos os envolvidos com sua realização, um aperfeiçoamento da formação inicial de docentes para a educação básica. Em particular destacamos a apreciação dos Licenciandos que participam deste Programa os quais declaram reiteradamente em seus depoimentos como o PIBID está contribuindo fortemente para sua formação profissional em função de propiciar contato direto com a realidade escolar nos inícios de seu curso, contato com a sala de aula e os alunos, possibilitando-lhes conhecer de perto a escola pública e os desafios da profissão docente. As Universidades federais, através dos seus formadores de professores, têm uma dívida há décadas para com a sociedade no que diz respeito à formação e desenvolvimento profissional dos profissionais da educação para o magistério nos níveis do EFM, de modo a atender às necessidades do sistema de ensino, em especial o sistema público (GATTI e ANDRÉ, 2013, p. 8).

Sobre o crescimento do PIBID no decorrer dos anos, a tabela 2 retirada de FONSECA (2018, p. 57) indica a quantidade de bolsistas participantes no programa no período de 2009 a 2014.

\begin{tabular}{|c|c|c|c|c|c|}
\hline \multicolumn{7}{|c|}{ Número de bolsistas por ano } \\
\hline Ano 2009 & 2010 & 2011 & 2012 & 2013 & 2014 \\
\hline 3.544 & 18.166 & 32.188 & 57.252 & 62.070 & 90.254 \\
\hline
\end{tabular}

Figura 2: Número de bolsistas (FONSECA, 2018, p. 57)

Percebemos que o Programa iniciou seus trabalhos em 2009 com mais de três mil bolsistas e em 2014 tinha mais de noventa mil bolsistas espalhados pelo território nacional, sejam eles coordenadores institucionais, coordenadores de área de gestão, coordenadores de área, Supervisores ou discentes de graduação, é evidenciado um enorme crescimento do programa em cinco (5) anos de atuação. A tabela 3 também retirada de FONSECA (2018, p. 58), indica tipos de bolsas, atuação dos sujeitos e remuneração: 
FONSECA, D. S.; de MOURA, E. M.

\begin{tabular}{|l|l|c|}
\hline \multicolumn{3}{|c|}{ Discriminação das bolsas do PIBID } \\
\hline \multicolumn{1}{|c|}{ Identificação } & \multicolumn{1}{|c|}{ Descrição } & $\begin{array}{c}\text { Valor da } \\
\text { Bolsa }\end{array}$ \\
\hline Iniciação à Docência & Estudantes de Licenciatura regularmente matriculados & RS 400,00 \\
\hline Supervisão & $\begin{array}{l}\text { Docente da escola pública de educação básica responsável } \\
\text { por acompanhar e supervisionar as atividades dos bolsistas }\end{array}$ & RS 765,00 \\
\hline Coordenação de Área & $\begin{array}{l}\text { Docente da IES responsável pelo planejamento, } \\
\text { acompanhamento e orientação dos bolsistas em sua área de } \\
\text { atuação acadêmica e pela articulação e diálogo com as } \\
\text { escolas púbicas no projeto }\end{array}$ & RS $1.400,00$ \\
\hline $\begin{array}{l}\text { Coordenadores de área } \\
\text { de Gestão de Projetos } \\
\text { Educacionais. }\end{array}$ & $\begin{array}{l}\text { Docente da IES responsável por auxiliar o coordenador } \\
\text { institucional }\end{array}$ & RS $1.400,00$ \\
\hline $\begin{array}{l}\text { Coordenação } \\
\text { Institucional }\end{array}$ & $\begin{array}{l}\text { Docente da IES responsável perante a CAPES pelo projeto } \\
\text { institucional zelando por sua instituição no andamento das } \\
\text { ações }\end{array}$ & RS $1.500,00$ \\
\hline
\end{tabular}

Figura 3: Discriminação das bolsas do PIBID (FONSECA, 2018, p. 58).

Já no ano de 2014, foram iniciadas as ações de um novo edital de 2013 envolvendo um maior número de IES.

\begin{tabular}{|c|c|c|c|c|}
\hline \multicolumn{5}{|c|}{ PIBID 2014 } \\
\hline & IES & Campi & Subprojetos & Bolsistas \\
\hline Norte & 27 & RS 95,00 & 300 & 9103 \\
\hline Nordeste & 56 & R\$ 232,00 & 780 & 28019 \\
\hline Centro-Oeste & 21 & RS 110,00 & 381 & 8894 \\
\hline Sudeste & 114 & R\$ 243,00 & 849 & 25381 \\
\hline Sul & 66 & R\$ 175,00 & 687 & 18857 \\
\hline Total & 284 & R\$ 855,00 & 2997 & 90254 \\
\hline
\end{tabular}

Figura 4: PIBID 2014 - Fonte: Relatório de Gestão Capes 2009-2013.

Temos 284 Instituições de Ensino Superior (IES) públicas ou privadas, espalhadas pelo país atuando no PIBID. Deste quantitativo, 150 IES públicas distribuídas em níveis federais, estaduais e municipais, e 134 IES privadas, sejam com ou sem fins lucrativos.

A evidência do alcance de atuação do PIBID se dá pelo número de IES atendidas neste novo edital de 2013, edital $n^{\circ}$ 61/2013 CAPES, de 02 de agosto de 2013: para instituições públicas, comunitárias e privadas com bolsistas do ProUni. O mapa na Figura 5 nos mostra o posicionamento geográfico destas IES.

Desde o século passado, ficava evidente uma necessidade de ter um número maior de Universidades federais em relação ao tamanho do território nacional e sua população. Concordamos com Gonçalves (2000, p.21):

As Universidades federais, através dos seus formadores de professores, têm uma dívida há décadas para com a sociedade no que diz respeito à formação e desenvolvimento profissional dos profissionais da educação para o magistério 


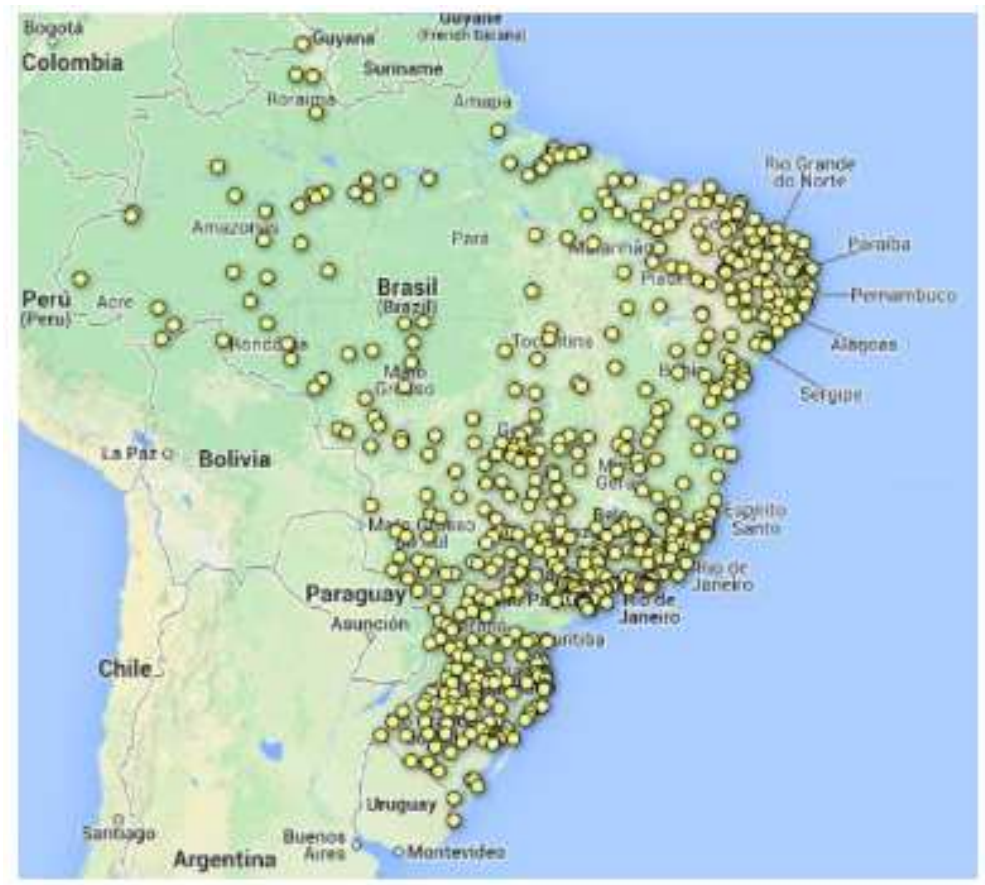

Figura 5: PIBID em 2014. Fonte: Relatório de Gestão da CAPES 2009-2013.

nos níveis do EFM, de modo a atender às necessidades do sistema de ensino, em especial o sistema público (GONÇALVES, 2000, p.21).

O crescimento da rede federal de ensino neste novo século, pela ampliação dos Institutos ou das Universidades, possibilitou uma grande entrada para todos os cursos espalhados pelo país, através de ações como o Exame Nacional do Ensino Médio (ENEM) como forma de ingresso nas Universidades e também a reestruturação e expansão das Universidades Federais (REUNI), que ampliou a interiorização das instituições públicas de ensino superior. Hoje, temos 63 Universidades Federais (UF) distribuídas nos 26 Estados e no Distrito Federal. Não entram nestes números as 5 novas Universidades Federais recentemente criadas, em: Catalão; Jataí; Delta do Parnaíba; Rondonópolis e Norte do Tocantins.

A maioria das UF se concentra no lado direito do mapa na Figura 6, deixando um imenso vazio que compreende principalmente as regiões centro oeste e norte do país. Isso nos implica a ressaltar a importância de possuir um edital que contemple todo o país, no sentido de possibilitar que todas as regiões sejam atendidas, atentos a atender as especificidades de cada região, pois em alguns casos a diferença regional é tamanha que não parece tratar-se de uma só nacionalidade. 


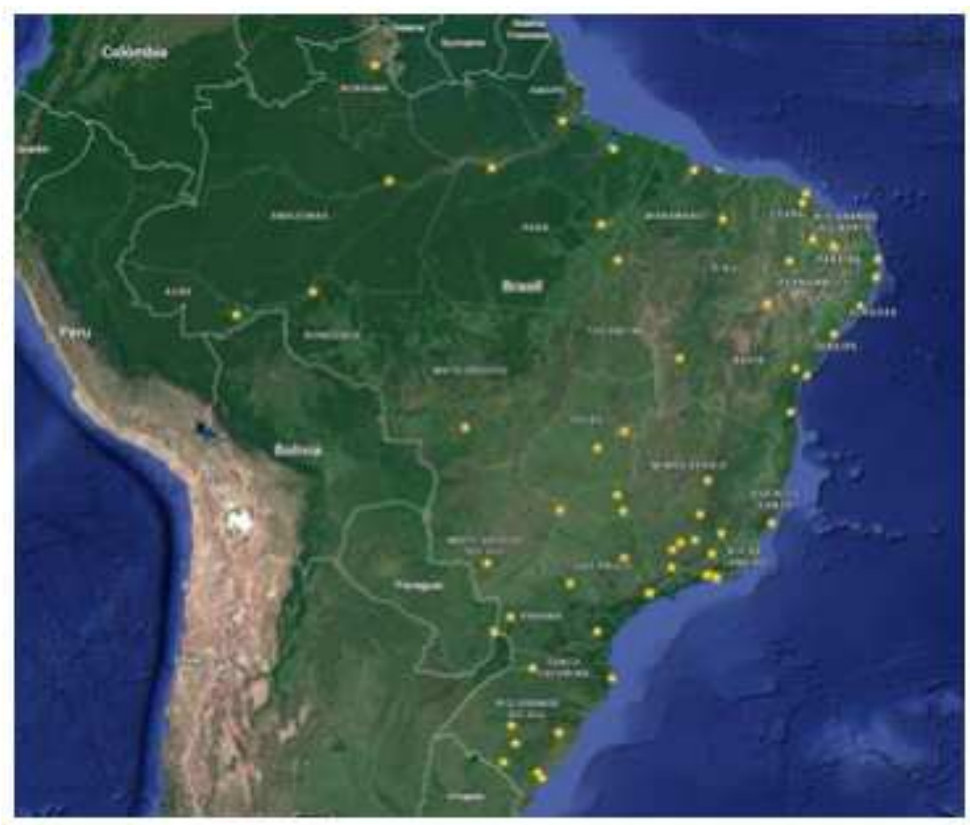

Figura 6: Mapa do Brasil com as 63 UF em 2015 (FONSECA, 2018, p. 60)

\section{Tecnologias digitais no PIBID}

Buscamos entender se o PIBID tem contribuído para o empoderamento tecnológico de bolsistas da licenciatura. Poderia o programa contribuir na criação de uma cultura tecnológica?

Pensamos que uma cultura só pode ser chamada como tal se ela implica na equidade de hábitos e/ou capacidades adquiridos por todos os membros de uma comunidade a que ela pertença. Desta forma, observamos que a tecnologia ainda não se faz cultural dentro do cenário educacional brasileiro, devido a uma série de fatores tanto estruturais quanto sociais, mas principalmente pela disparidade de cada indivíduo, não limitada a idade ou ofício, sobre a intimidade com as tecnologias. Moura \& Fonseca in Fonseca (2018, p. 192) nos deixam a Figura 7 que exemplifica essa individualidade.

Nela, a ligação das pessoas, representadas pelos círculos periféricos, com o uso de TDIC são desiguais já que cada indivíduo possui habilidades especificas para o uso das tecnologias. Esta distância tende a diminuir naturalmente com o passar do tempo, tanto pela aproximação natural que estamos vivenciando na sociedade moderna, mas, principalmente, pelas futuras gerações que serão os Nativos Digitais, termo usado por Prensky (2009) e Manuel Castells (2002) para denominar aqueles que nascem nesse mundo tecnológico. Pensar a relação desigual evidenciada pela figura envolve, principalmente na 


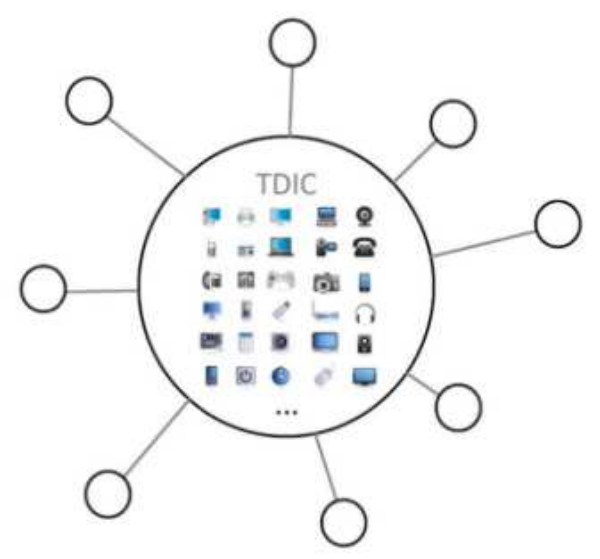

Figura 7: Perspectivas de Ensino Aprendizagem com TDIC no Século XXI (MOURA \& FONSECA in: FONSECA, 2018, p. 192).

educação, entender, considerar e respeitar cada ligação individual para que o uso da tecnologia como metodologia de ensino.

O uso de ferramentas tecnológicas dentro das salas de aula se torna mais frequente com o desenvolvimento da própria tecnologia. Acreditamos que essa inserção no contexto escolar além de inevitável é também necessária. Tal ideia é defendida por Gravina e Santarosa (1998) quando afirmam que

[...] não é difícil pensar em um futuro para a Educação em que os ambientes informatizados vão ultrapassar sua função de simples ferramentas de apoio ao pensar, $[\ldots]$, passando então a ter papel fundamental no próprio desenvolvimento de novas capacidades cognitivas do indivíduo, ainda hoje não imaginadas (GRAVINA e SANTAROSA, 1998, p.22).

Para buscar entender se o PIBID tem ainda contribuído para um empoderamento tecnológico de bolsistas da licenciatura e professores, verificamos em nossa amostragem 14 universidades federais (16 campi diferentes), de todas as regiões brasileiras, representando as 50 que possuem subprojeto de matemática que poderiam ser nosso campo empírico. Decidimos por diminuir tal amostragem nesse caso pois seria inviável uma análise maior nesse documento, mas claro, aos interessados, análises de todos os subprojetos podem ser encontrados nas pesquisas completas de pós-graduação desses autores, de fácil descoberta na internet. Também realizamos entrevistas com um Professor Supervisor (PS) de cada instituição para triangular e verificar dados colhidos nos documentos dos subprojetos. As universidades pesquisadas podem ser verificadas na listagem abaixo.

- Universidade Federal do Rio de Janeiro (UFRJ), campos Nova Iguaçu e Seropédica;

- Universidade Federal do Espírito Santo (UFES); 
- Universidade Federal de Juiz de Fora (UFJF);

- Universidade Federal de Uberlândia (UFU);

- Universidade Federal do Triângulo Mineiro (UFTM);

- Universidade Federal de São Paulo (UNIFESP)

- Universidade Federal de Pernambuco UFPE

- Universidade Federal do Rio Grande do Norte UFRN

- Universidade Federal da Bahia UFBA

- Universidade Federal de Campina Grande (UFCG);

- Universidade Tecnológica Federal do Paraná (UTFPR), campos de Toledo e Cornélio Procópio;

- Universidade Federal do Pampa (UNIPAMPA);

- Universidade Federal do Tocantins (UFT);

- Universidade Federal de Mato Grosso do Sul (UFMS).

Observamos nos subprojetos a constituição de estratégias formativas que possibilitassem a produção de saberes docentes relacionados ao processo de ensinar e aprender Matemática com uso de tecnologias. Mensurar esse empoderamento nos alunos de graduação implica em analisar o processo de produção dos licenciandos, e nos parece sensato utilizar a divisão de produtos proposta pelo próprio relatório de atividades, documento apresentado todo final de semestre de trabalhos do PIBID. Tal documento relaciona as atividades desenvolvidas por tipo, nos seguintes indicadores: Produções Didático-Pedagógicas; Produções Bibliográficas; Produções Artístico-Culturais; Produções Desportivas e Lúdicas; Produções Técnicas, Manutenção de Infraestrutura e Outras.

Apesar de nos referirmos ao trabalho dos bolsistas como produção e produto, é importante discutir qual é o sentido dessas produções ou desses produtos para os bolsistas. No PIBID, tais produtos têm sido apenas uma forma de quantificar os resultados do Programa, o que achamos ser um aspecto bastante negativo, inclusive para a formação de professores. A mera quantificação de produtos é uma contradição e nega os referenciais críticos acerca da Educação. Por isso, e também por não ser nossa intenção nesse artigo nos alongarmos em análise de produtos, faremos um diagnóstico dos sentidos dessas produções ou produtos e o que de fato contribuiu para a formação crítica de bolsistas de um 
subprojeto escolhido por nós, que pode nos dar pistas de caminhos interessantes a seguir. O primeiro passo foi entender o cenário tecnológico a que estamos nos credenciando a analisar. Suspeitamos que a cultura digital ainda não deva estar estabelecida em âmbito nacional, e além disso, acreditamos que as diferenças de regiões poderiam mostrar contrastes nos resultados. Mesmo porque não existe uma receita consagrada aos professores como medida certa para aplicação de Tecnologias Digitais de Informação e Comunicação (TDIC) no ensino de matemática, mas sim, caminhos favoráveis para esta prática iniciando pelo trabalho colaborativo entre os docentes em seus locais de trabalho.

Quando pensamos então que as licenciaturas, de alguma forma, dão aparatos para uma experiência tecnológica, mínima que seja, para os futuros professores, trazendo, além de discussão, também práticas com as tecnologias, nos confrontamos com uma realidade bem conhecida. A prática da racionalidade técnica é mais comum do que gostaríamos. Quando o professor formado se depara com uma situação fora de sua zona de conforto, ele geralmente tende a seguir o que é ditado pelos "especialistas" na universidade.

Bedin (2012) vem dissertar sobre isso quando fala da formação de professores, dizendo que a questão é

[...] a forma de ensino e os conteúdos trabalhados, que muitas vezes prendem o aluno à racionalidade técnica, aprimorando-os em conteúdos de natureza declarativa, em que se acredita que irão "aplicar" - mais tarde - tais conteúdos em seus estágios. Desse modo, os futuros professores, ao concluírem a formação inicial, aprendem no ofício da sua profissão que tais conteúdos não foram aprofundados e que para aquele momento se tornam insuficientes, ocorrendo o choque com a realidade (BEDIN, 2012, p. 56).

Nas reuniões periódicas entre PS e os bolsistas licenciandos, esse incômodo era externado pelos bolsistas, bem resumido numa das falas

O Curso de Licenciatura em Matemática aqui oferece disciplinas que não visam à formação docente. Algumas disciplinas não são importantes para se aprender as disciplinas da Educação Básica. O corpo docente da área da Educação é bem pequeno, a justificativa disso eu não sei qual é. As disciplinas chamadas pedagógicas, não te ensinam a lecionar um determinado conteúdo matemático. Tudo o que se faz é sentar em círculos e discutir textos (Entrevista PS2 - região sudeste).

No que diz respeito a formação, se hoje temos constatado que muitos não têm desenvolvimento apropriado para o uso de TDIC, podemos entender que para os professores supervisores, muito há anos na docência, tão pouco tiveram uma formação diferente, seja na época de graduação, seja no decorrer de sua formação continuada como docente na carreira. Segue abaixo respostas dos professores supervisores que sintetizam e corroboram com esta análise:

Vou fazer 53 anos, então, quando eu comecei a fazer a minha graduação ainda 
não tinha esses computadores de pequeno porte que nós temos hoje muito menos notebook. Eu trabalhei na época com grande porte que hoje em dia praticamente só empresas grandes que trabalham (Entrevista PS1 - região norte).

Outra

A gente fazia alguma programação até naquele MSDOS; você aprendia programar uma soma, programar uma subtração, programar uma expressão matemática, mas era só isso que você aprendia; na época em que eu fiz mestrado que parece que estava muito em ênfase o CABRI (Entrevista PS5 ? região sudeste).

Outra

Então, foi nenhum; nunca tive contato na educação básica com tecnologias digitais; Tecnologias digitais na geração que eu venho não tinha isso; lecionei por muitos anos nas Escolas, na época que eu lecionava não tinha é aparato tecnológico nenhum; nem calculadora tinha; história da matemática, também não tinha essa interface com tecnologia digital; vim lecionar aqui na UF; eu praticamente que estruturei um laboratório; meu contato começou meio por ai na lousa digital (Entrevista PS9 - região sul).

Podemos dizer que a tecnologia chegou primeiro nas escolas como uma política pública pelos programas ProInfo e depois na academia, já que as escolas são equipadas e na maioria dos casos não faz o uso das tecnologias, embora os governos tenham investido em diversas formações continuadas de professores e de gestores de Educação Básica, mas ainda falta formação nos cursos de Licenciatura, como vimos. Não temos hoje na maioria dos cursos de Licenciatura em Matemática, a disciplina de TDIC, ou similar, como obrigatória em sua grade. Já segundo o PS11, essa situação passa por uma questão de caráter estrutural, como podemos comprovar em uma das falas

\footnotetext{
É a questão estrutural mesmo, das Escolas que a gente atua, na própria universidade, então as vezes a gente tem uma proposta interessante e aí acaba que esbarra em problemas estruturais ou burocráticos assim, há laboratórios na Escola que não podem ser usados porque é uma pessoa tem uma senha, essa pessoa é um funcionário da secretaria e atende a todo Estado. Esses são alguns dos nossos problemas, mas que são problemas que a gente tem tentado superar, driblar, sair com as alternativas (Entrevista PS11 - região sudeste).
}

O fato é que os problemas estruturais e de caráter formativo são evidentes em escolas e universidades. Ao aparecerem eles precisam, de alguma forma, serem confrontados. Sem dúvida, professores precisam integrar conhecimentos tecnológicos, pedagógicos e de conteúdo MISHRA e KOEHLER (2006, p.1022) destacam as dificuldades iniciais dos professores quando nos dizem que:

Embora nem todos os professores tenham abraçado essas novas tecnologias para uma série de razões, incluindo um medo de mudança e falta de tempo e 
apoio, o fato de que essas tecnologias estão aqui para ficar não pode ser duvidado. Além disso, o rápido ritmo de evolução destas novas tecnologias digitais impede-os de se tornarem "transparentes" em breve. Os professores terão que fazer mais do que simplesmente aprender a usar ferramentas atualmente disponíveis; eles também terão que aprender novas técnicas e habilidades como as tecnologias atuais se tornam obsoletas (MISHRA e KOEHLER, 2006, p.1022).

Então, podemos pensar que não são o aprendizado na técnica e no manuseio da ferramenta que pode estar o caminho de fazer com que os professores realmente se tornem conhecedores e empregadores das TDIC na sala de aula. Buscamos então outros caminhos.

Um dos PS trouxe uma velha solução para tratar sobre como levar ou tratar a tecnologia nas escolas que os licenciandos atuavam, e de quebra trabalhou a interferência da universidade sobre os problemas vistos na escola. O Coordenador de um dos subprojetos justificou a "liberdade"que dava aos bolsistas na construção de estratégias para enfrentar os problemas vistos por eles na escola, deixando totalmente à escolha do licenciando a ferramenta e como usá-la nas suas intervenções na escola. Deixar que eles ficassem livres em seu novo ambiente, interferindo raras vezes, e na maioria delas com conselhos e conversas trazidas pelos próprios licenciandos, dava a impressão a esses licenciandos de que ele pouco se importava. Na verdade, em suas palavras, deixou claro que era sua opção tentar interferir o mínimo possível, para evitar que o trabalho na escola fosse uma extensão de suas atividades na universidade.

\footnotetext{
Chegou a brincar que se ele quisesse como coordenador do Projeto colocaria mil e um projetos na escola, pois tinha bagagem e ferramentas pra isso, mas que tal atitude transformaria os bolsistas em meros reprodutores das falas e ideais dele, o que não era o intuito do Projeto, e nem mesmo dele (Nota de Campo Pesquisadores).
}

De fato, se o PS fosse interferir de maneira que os projetos que os bolsistas fossem aplicar na escola viessem pensados por ele, mesmo com o conhecimento que possui do cotidiano escolar, a intervenção seria da Universidade para a escola, e não partindo da própria escola. Deixar os Pibidianos pensarem, refletirem, e se desafiarem na prática docente, analisando a utilização das tecnologias por cada um, geram uma produção de pensamentos e uma construção, ou reconstrução, da identidade profissional, por meio de saberes coletivos que levam a não racionalidade técnica. Mas ainda assim, a solução passou justamente pela observação dos licenciandos com relação aos problemas da Educação Básica discutidos na universidade. O que foi proposto pelo PS foi a prática de reflexões nos encontros seguintes sobre temas relacionados aos problemas encontrados na escola. Para isso, foi feita uma seleção de textos que seriam discutidos por todos, sendo um, entre os Pibidianos, responsável por vez da apresentação do texto.

Não viemos dizer que a tomada de decisão de buscar um referencial teórico seja ruim. 
Ao contrário, achamos essencial um bom conhecimento de referenciais teóricos para qualquer trabalho docente. Apenas reforçamos que a Universidade, aqui representada pelo PS, geralmente recorre às discussões de textos, referenciais teóricos, sobre os assuntos que estão em foco, quase que como solução para toda e qualquer situação. Ainda assim, houve uma perceptível diferença nesse caso. Ao invés de serem textos sobre problemas igualmente gerais e atuais, os textos lidos e discutidos pelos Pibidianos nas reuniões a partir daquela, serviram de inspiração para as ações que viriam a seguir. Mas se a metodologia usada foi a mesma, o que fez a diferença?

O destaque está nos estudos teóricos voltados para a discussão de questões presentes no desenvolvimento do PIBID, trazidos tanto pelo PS quanto pelos licenciandos. A maneira pontual com que os textos foram discutidos em um foco muito aproximado do real momento desses Pibidianos fez com que o resultado fosse diferente daqueles alcançados na Licenciatura. Os Pibidianos, inspirados pelas discussões frequentes, desenvolveram várias ações baseadas nessa literatura. E esse era o espírito do PIBID. Inserir-se no cotidiano escolar, trazer as discussões desse ambiente para a Universidade e voltar com ações para minimizar qualquer situação que se apresentasse negativamente ao sistema educacional.

\footnotetext{
O subprojeto pode ser um agente contribuinte na formação do professor, caracterizando como objeto de estudo e reflexão. Ao participar do Projeto, o futuro professor passa a enxergar a Educação com outro olhar, procurando entender a realidade da escola e o comportamento dos alunos, dos professores e dos profissionais que a compõem. Com isso faz uma nova leitura do ambiente (escola, sala de aula, comunidade), procurando meios para intervir positivamente, apoiados pelo ensino da Universidade. (Entrevista PS10 - região nordeste).
}

A trajetória do grupo foi caracterizada por movimentos em espaços diversos de formação. Assim, entendemos que os saberes produzidos no grupo também podem ser caracterizados pelas características e possibilidades de cada espaço percorrido. Mediados por esses espaços de formação, os indivíduos contribuem com seus saberes singulares na construção de um saber coletivo e, por outro lado, esses saberes produzidos coletivamente possibilitam o desenvolvimento do saber do indivíduo. O fato de poder trabalhar com alunos pouco motivados tem sido um desafio para os bolsistas do PIBID. A importância da troca permeada por tecnologias possibilita a barganha de descobertas, onde se socializam ideias com pessoas diferentes em vez de se fecharem por uma educação impositiva, muitas vezes, por fazer o que não é adequado ou atrativo. Dessa forma, esse espaço contribuiu para uma melhoria na Educação. De maneira geral, o PIBID se tornou importante como ferramenta para empoderar tecnologicamente a formação dos futuros professores, bem como dos que já atuavam nas escolas. Aos que se interessarem pelas ações e produções, fica o convite de buscar nas dissertações e teses dos autores maiores informações. 


\section{Considerações finais}

As TDIC, como espaço de formação dos alunos da escola pública, foram amplamente usadas pelos Pibidianos em vários subprojetos de matemática em todo o país. Mas vale destacar a que a relevância tanto para a formação do futuro professor, quanto para os retornos às escolas, era maior quando a questão do trabalho com a informática na Educação surgia a partir da realidade e necessidade da escola, que continha aparato para uma prática tecnológica. Dessa forma, pensamos que o PIBID pode propiciar espaços de autoria dos licenciandos no contexto da cultura digital e que as pesquisas puderam ainda revelar a complexidade de formar um professor-autor que possibilite que seus alunos produzam em um contexto da cultura digital.

As ações e reflexões realizadas pelos vários bolsistas, graduandos e formadores, mostram o grau de maturidade de suas atitudes diante as adversidades encontradas no trabalho com as TDIC. As considerações retiradas de entrevistas, questionários e anotações desses pesquisadores constituídas durante a realização dos estudos, demonstram que os indivíduos enrolados no programa têm consciência de que a Educação Digital deve ser considerada sob a uma lógica baseada no protagonismo dos alunos, conflitante assim com a lógica escolar do professor como transmissor do conhecimento. Para Alonso (2008):

Do ponto de vista pedagógico, o uso das TIC no contexto escolar e as significações sobre elas têm implicado transformações que relativizam a função do professor como transmissor de conhecimento, deslocando o centro da questão para o "protagonismo" dos alunos. O problema é que a escola, como instituição, está ainda marcada pela lógica de transmissão, fazendo colidir com a lógica das TIC e a lógica escolar (ALONSO, 2008, p.755).

Tais trabalhos com as TDIC, por exemplo, (re)significaram o sentido das produções nos Pibidianos.

\footnotetext{
Pude perceber um pouco sobre a importância de trabalhar a Matemática utilizando tecnologia, como softwares e outra, pois com o surgimento da acessibilidade aos meios tecnológicos, por parte da escola, nos proporciona algo que desperta no aluno um interesse maior pela disciplina e também esses meios facilitam a aprendizagem do aluno, pois por meio deles a percepção do que e abstrato na Matemática torna se mais fácil à ideia para o aluno. (Entrevista PS2 - região sudeste).
}

Nesta investigação, constatamos existir um processo de autoria dos bolsistas PIBID, no que se refere ao desenvolvimento do trabalho educativo na cultura digital. As discussões a partir dessas ações nos possibilitaram entender que as obras produzidas por eles são um produto do seu aprendizado e esse resultado pode ser discutido a partir dos significados e sentidos que os Pibidianos atribuem às TDIC. Todo esse trabalho com as mídias nos atentou para o amadurecimento do programa, levando em conta o pensamento crítico reflexivo, a autonomia e a autoria. Para tal, buscavam: 


\begin{abstract}
Conceber estratégias metodológicas que facilitem a compreensão e interpretação de conceitos e que desafiem os estudantes a solucionar problemas complexos e que possam ser usados, reutilizados e combinados com outros objetos para formar um ambiente de aprendizado rico e flexível. Essas atividades pedagógicas digitais devem evidenciar os aspectos lúdicos, de interação e de experimentação que deveriam estar presentes em qualquer processo de aprendizagem significativa (PRATA; NASCIMENTO; PIETROCOLA, 2007, p. 107).
\end{abstract}

Essas práticas desencadearam uma série de benefícios e características desenvolvidas de acordo com a experiência de cada um. Entre as mais comuns ao grupo destacamos: aperfeiçoamento da oratória e escrita; autonomia; trabalho em equipe; disposição para pesquisar; explanação de ideias; capacidade de planejar; disposição para pesquisar; Capacitação da docência por meio da prática; organização; responsabilidade; criatividade. Tal amadurecimento também se deve à compreensão do Cotidiano Escolar; Importância dada ao Trabalho Coletivo; Diálogo com Pensamentos Diferentes; Reflexão Sistemática Sobre as Práticas Pedagógicas; Responsabilidade Individual e Coletiva; Desenvolvimento da Criatividade; Reflexão Crítica das Políticas Públicas da Educação.

\title{
Referências
}

[1] ALONSO, Kátia Morosov. Tecnologias da informação e comunicação e formação de professores: sobre rede e escolas. Educação Sociedade, Campinas, v. 29, número especial, CEDES, p. 747 - 768, 2008.

[2] BALDIJÃO, C. E. T.; ZULEIDE, A., A Educação no Governo Lula. (Brasil em Debate v.6). São Paulo: editora Fundação Perseu Abramo, 2011.

[3] BEDIN, Everton. Formação de professores de Química: um olhar sobre o PIBID da Universidade Federal de Uberlândia. 2012. Dissertação (Mestrado em Química). Instituto de Química, Universidade Federal de Uberlândia, Uberlândia, 2012.

[4] BRASIL. Decreto no 7.219, de 24 de junho de 2010. Dispõe sobre o Programa Institucional de Bolsa de Iniciação à Docência PIBID e dá outras providências. Diário Oficial da União, n. 120, seção 1, p. 4 - 5, 2010.

[5] BRASIL. DEB Relatório de Gestão 2009-2013. Disponível em: $\ll$ http://capes.gov.br/educacao-basica/capespibid/relatorios-e-dados $\gg$. Acesso em: 06 set. 2019.

[6] CASTELLS, M. A sociedade em rede. São Paulo: Paz e Terra, 1999. 
[7] D’ AMBRÓSIO, U. Educação Matemática: Da Teoria à Prática. Campinas: Papirus, 1996.

[8] DANTAS, L. K. Iniciação à docência na UFMT: Contribuições do Pibid na Formação de professores de Química. 2013. Dissertação (Mestrado em Educação), Instituto de Educação, Universidade Federal do Mato Grosso, Cuiabá, 2013.

[9] FONSECA, D.S. Formação de professores de matemática e as tecnologias digitais da informação e comunicação no contexto do PIBID. Tese (Doutorado em Educação Matemática) Programa de Pós-Graduação em Educação Matemática da Universidade Anhanguera de São Paulo, São Paulo, 2018.

[10] GATTI, Bernadete A. et al. Um estudo avaliativo do Programa Institucional de Bolsa de Iniciação à Docência (Pibid). São Paulo: FCC/SEP, 2014.

[11] GRAVINA, Maria Alice; SANTAROSA, Lucila Maria. A aprendizagem da Matemática em Ambientes Informatizados. IV Congresso RIBIE. Brasília, 1998. Disponível em: « http://euler.mat.ufrgs.br/ edumatec/artigos/a1.pdf $\gg$. Acesso em: 04/05/2007.

[12] MISHRA, Punya; KOEHLER, Matthew J. Technological pedagogical content knowledge: A framework for teacher knowledge. Teachers College Record, 108(6), 1017-1054, 2006.

[13] MOURA, E. M.de. O programa institucional de bolsa de iniciação à docência PIBID na formação inicial de professores de Matemática. 2013. Dissertação (Mestrado em Educação), Programa de Pós-Graduação em Educação, Universidade Federal de Uberlândia, Uberlândia, 2013.

[14] PRATA, C. L.; NASCIMENTO, A. C. A; PIETROCOLA M. Políticas para fomento de produção e uso de objetos de aprendizagem. In PRATA, C. L.; NASCIMENTO, A. C. A. (Org.). Objetos de aprendizagem: uma proposta de recurso pedagógico. Brasília: MEC; SEED, 2007. p. 107-121. 